\title{
SYMPTOMS SUGGESTIVE OF COVID-19 IN RHEUMATIC PATIENTS USING ANTIMALARIALS OF MÁRIO PINOTTI PROJECT II IN MANAUS/ AMAZONAS
}

Cecília Tizatto Barroso ${ }^{1, \star}$, Joelma Moreira Belas Torres ${ }^{1}$, Samuel Elias Basualto Dias ${ }^{1}$, Vitória Miki Pang Takatani', Clara Pinheiro Martins ${ }^{1}$, Gabriella Bacellar Marques', Bárbara Letícia Costa Corrêa1', Gabriela Alarcón Alcântara', Bruna Borges Santos', Gabriel Antônio de Lima Cerqueira', Bruna Guimarães Dutra', Laura Ribeiro Aref Kzam¹, Andrezza Mendes Franco', Helena Lúcia Alves Pereira', Sandra Lúcia Euzébio Ribeiro

1.Universidade Federal do Amazonas, Manaus (AM), Brazil.

*Corresponding author: cecilia.tizattto@gmail.com

\section{BACKGROUND}

In 2020, the SARS-CoV-2 infection, also known as coronavirus disease 2019 (COVID-19), was considered a pandemic with a great impact on global health. In this context, Mário Pinotti Project II (MPII) aimed to compare the frequency of this infection between rheumatic patients using antimalarials and a control group to evaluate the preventive effect of antimalarials in COVID-19. This study has the objective of describing symptoms suggestive of COVID-19 among rheumatic patients at the research center located in the city of Manaus, Amazonas, during the study.

\section{MATERIALS AND METHODS}

It is a prospective observational study, based on the analysis of data from patients with immune-mediated diseases of MPII, organized by the Brazilian Society of Rheumatology, locally in Manaus. Symptoms were analyzed using the Brazilian Ministry of Health (BMH) clinical criteria to define COVID-19 cases, as well as other viral infection symptoms. The worsening of rheumatological symptoms after the start of these episodes was also investigated. The study was approved by the ethical committee.

\section{RESULTS}

During the follow-up between April to September 2020, it was observed that 174/311 rheumatological patients reported symptoms suggestive of COVID-19, with duration ranging from 5 to 28 days, a median of 7.6 days. The first episode of these patients included headache (56.9\%), asthenia (50.6\%), coryza (44.2\%), cough (42.5\%), fever (41.9\%), sore throat (33.9\%), reduction of taste (32.7\%), loss of smell (31\%), dyspnea (25.8\%), diarrhea (16.1\%), dizziness (10.3\%), nausea (13.2\%) and other unspecific symptoms (13.8\%) were also reported. In addition, 48/174 patients reported worsening of rheumatological symptoms after the start of the symptoms suggestive of COVID-19.

\section{CONCLUSION}

In the present study, the most frequent symptoms suggestive of COVID-19 were headache, asthenia, coryza, cough, and fever. Smell and taste dysfunction were not as frequent as described in the literature. Additionally, the worsening of rheumatic disease after these symptoms could be correlated to increasing of rheumatic disease activity after viral infection, as already seen with other viruses. 